\title{
Fitossociologia em uma mata de restinga paludosa na Mata do Totó, Pelotas, RS
}

\author{
Tiago Schuch Lemos Venzke ${ }^{1^{*}}$, Gabriel Kaster Herter ${ }^{2}$, Vilmar Luciano Mattei ${ }^{3}$ \\ ${ }^{1}$ Rua Dr. Cassiano, 633, Centro, 96015-700, Pelotas, RS, Brasil \\ ${ }^{2}$ Rua Gonçalves Chaves 3500, Centro, 96015-560, Pelotas, RS, Brasil \\ ${ }^{3}$ Universidade Federal de Pelotas, Departamento de Fitotecnia, Faculdade de Agronomia,Campus Universitário, S/N, Caixa Postal 354, CEP 96160-000 Capão \\ do Leão, RS, Brasil
}

\begin{abstract}
Árvores
Ecologia Florestal

Floresta Turfosa

Planície Costeira

Praia do Laranjal

\section{Index terms: \\ Trees \\ Forest ecology \\ Swamp Forest \\ Coastal Plain \\ Laranjal beach}

"Autor correspondente:

venzke.tiago@gmail.com

Termos para indexação:

Histórico do artigo:

Recebido em 24/01/2014

Aprovado em 23/03/2015

Publicado em 30/06/2015

doi: $10.4336 / 2015 . p f b .35 .82 .648$
Resumo - Foi analisada a florística e a estrutura do componente arbóreo de uma mata de restinga paludosa na Praia do Totó, porção sul da Laguna dos Patos, Município de

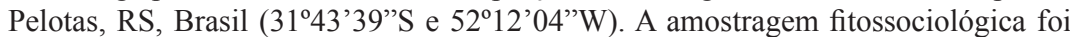
realizada em uma área de 0,1 ha. Foram incluídos todos os indivíduos com $D A P \geq 4,8 \mathrm{~cm}$. Foi encontrada uma riqueza de 23 espécies, 20 gêneros e 15 famílias, sendo duas espécies ameaçadas de extinção. A densidade foi estimada em 3.480 ind. ha ${ }^{-1}$. As espécies mais importantes na estrutura da floresta foram Ocotea sp., Myrcia multiflora, Psidium cattleianum, Ocotea pulchella, Myrsine lorentziana, Citharexyllum myrianthum, Ilex dumosa, Syagrus romanzoffiana, Guapira opposita e Sebastiania brasiliensis. A diversidade (H') foi de 2,174 nats.ind. ${ }^{-1}$ enquanto que a equabilidade (J) foi de 0,684 . A estrutura da floresta, o número de táxons e a diversidade foram similares aos encontrados em inventários realizados nas matas de restinga paludosa na Planície Costeira do Brasil. Estes parâmetros devem ser considerados no licenciamento ambiental e em projetos de restauração ecológica dessa formação florestal.

\section{Phytosociology of a coastal peat forest of the Toto Beach, Municipality of Pelotas, RS, Brazil}

\begin{abstract}
Floristic composition and structure of the tree component were analyzed in a coastal peat forest of the Toto Beach, located in the southern region of Lagoa dos Patos (31 $1^{\circ} 43^{\prime} 39^{\prime \prime}$ e $\left.52^{\circ} 12^{\prime} 04^{\prime \prime} \mathrm{W}\right)$. The phytosociological sampling was conducted on a sample area of $0.1 \mathrm{ha}$. All trees with $\mathrm{DBH} \geq 4.8 \mathrm{~cm}$ were included. The species richness found was equivalent to 23 species distributed in 20 genera and 15 families. Two endangered species were sampled. The total tree density estimated for one hectare was equivalent to 3,480 trees. The most important species in the forest structure were Ocotea sp., Myrcia multiflora, Psidium cattleyanum, Ocotea pulchella, Myrsine lorentziana, Citharexyllum myrianthum, Ilex dumosa, Syagrus romanzoffiana, Guapira opposita and Sebastiania brasiliensis. The species diversity estimated by the Shannon index was 2,174 nats.ind.-1 and evenness $(J)$ was 0.684 . The forest structure, number of taxa and diversity are similar to other surveys carried out in swamp forests of southern and southeastern Brazil. These parameters must be considered in the environmental licensing and ecological restoration projects of this forest type.
\end{abstract}




\section{Introdução}

A vegetação de restinga é considerada legalmente uma formação vegetal associada ao Bioma da Mata Atlântica (Brasil, 2006) e está distribuída sobre a região geomorfológica da Planície Costeira. Conforme Resolução $n^{0} 7$ do CONAMA (Brasil, 1996), a vegetação nas restingas é um conjunto de comunidades, fisionomicamente distintas, sob a influência marinha e fluvio-marinha que estão distribuídas em mosaico. Ocorrem em áreas de grande diversidade ecológica, sendo consideradas comunidades edáficas por dependerem mais da natureza do solo do que do clima. Brasil (2012) define a restinga como comunidade que recebe influência marinha, com cobertura vegetal em mosaico, encontrada em praias, cordões arenosos, dunas e depressões, apresentando, de acordo com o estágio sucessional, estrato herbáceo, arbustivo e arbóreo, este último mais interiorizado.

Para as restingas no Rio Grande do Sul, Waechter $(1985,1990)$ classificou a vegetação lenhosa em quatro comunidades arbóreas básicas: comunidades savânicas (palmares ou butiazais), matas ciliares, matas arenosas e matas paludosas. As matas paludosas são formações vegetais que ocupam as partes encharcadas e de menor cota no terreno.

Estas se desenvolvem em solos orgânicos relacionados a depósitos paludais ou turfáceos (Waechter, 1985, 1990), encharcados ao longo do ano, o que favorece a saturação hídrica e o acúmulo de matéria orgânica (Waechter \& Jarenkow, 1998). São naturalmente fragmentadas e na costa do Rio Grande do Sul são formações vegetais insulares, de maneira geral, contíguas às matas arenosas que possuem melhor drenagem (Porto \& Dillenburg, 1986; Dorneles \& Waechter, 2004; Venzke et al., 2012).

As comunidades vegetais das matas paludosas na Planície Costeira do Rio Grande do Sul (Waechter \& Jarenkow, 1998; Kindel, 2002; Dorneles \& Waechter, 2004; Venzke et al., 2012) demonstram uma comunidade de baixa altura, reduzida diversidade, alta densidade e limitada à presença de poucas espécies habitando o meio ambiente. Conforme estudos realizados no Brasil por Torres et al. (1994), Ivanauskas et al. (1997), Cattanio et al. (2002), Sztutman \& Rodrigues (2002), Teixeira \& Assis (2005), Carvalho et al. (2006); Scarano (2006); Loures et al. (2007); Zacarias et al. (2012); Martins et al. (2013), a vegetação arbórea em solos com encharcamento permanente também mostram essa tendência de parâmetros fitossociológicos. No entanto, ainda não existem trabalhos que descrevam a vegetação de mata paludosa na região do estuário da Laguna dos Patos.

Portanto, esse trabalho teve por objetivo descrever a vegetação florestal de área encharcada do estuário da Laguna dos Patos, buscando complementar o conhecimento dessas formações florestais brasileiras, disponibilizando dados sobre ecossistemas de referência para projetos de restauração ecológica em planos de manejo para conservação dessa importante tipologia florestal.

\section{Material e métodos}

\section{Área de estudo}

O estudo foi realizado no Balneário da Praia do Laranjal, Município de Pelotas, RS, em um remanescente conhecido popularmente como "Mata do Totó"

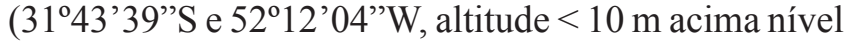
do mar). A mata está localizada às margens da Laguna dos Patos, sobre o terraço lagunar do Sistema Deposicional Laguna-Barreira IV (Tomazelli \& Villwock, 2005). Situa-se na região fitogeográfica das Áreas de Formação Pioneira com Influência Fluvial (IBGE, 1986, 2012). O remanescente possui cerca de $6.200 \mathrm{~m}$ de comprimento, largura média de $266 \mathrm{~m}$ e aproximadamente 160 ha de área, cuja configuração alongada estende-se paralela à margem da Laguna dos Patos. A distância do mar é de aproximadamente $48 \mathrm{~km}$. O local é protegido por legislação municipal que declara de valor paisagístico e ecológico a Mata do Totó (Pelotas, 1998).

A Mata do Totó possui importante função de corredor ecológico para o fluxo gênico entre os organismos de flora e de fauna (Venzke, 2005), ligando o complexo hídrico da Lagoa Pequena com a foz do Canal São Gonçalo. A vegetação está condicionada pela topografia: matas arenosas na parte alta da barreira e em solos com drenagem eficiente, e a mata paludosa nas partes baixas sobre o terraço lagunar, depressões do terreno e em áreas de drenagem deficiente (Venzke et al., 2012).

O clima da região é do tipo Cfa pela classificação do sistema de Köppen (1948). A temperatura média anual é de $17,8^{\circ} \mathrm{C}$, com médias mensais de $23,2^{\circ} \mathrm{C}$ para o mês mais quente (janeiro) e $12,4{ }^{\circ} \mathrm{C}$ para o mês mais frio (julho) conforme dados do convênio entre a Empresa Brasileira de Pesquisa Agropecuária e Universidade Federal de Pelotas. A precipitação média anual é de 
$1.367 \mathrm{~mm}$ e normalmente não ocorrem meses com déficit hídrico. As menores precipitações ocorrem em março $(97,4 \mathrm{~mm})$ e em novembro $(99,5 \mathrm{~mm})$ e as maiores em fevereiro e em julho, com 153,3 mm e $146 \mathrm{~mm}$, respectivamente (Temperatura média..., 2015).

\section{Amostragem da vegetação}

O levantamento do componente florestal foi realizado em área sem a presença de animais herbívoros domésticos (bovinos, equinos e ovinos). Assim a influência do pastoreio dos animais sobre a vegetação não compromete o desenvolvimento da estrutura da vegetação e sem prejuízo para a regeneração natural.

O método utilizado foi de parcelas sistemáticas. A amostragem do componente arbóreo foi realizada conforme Kindel (2002), segundo metodologia desenvolvida por Gentry (1982). Essa metodologia é adequada para descrever formações florestais paludosas (Kindel, 2002) e tem sido usada para descrever a variação dentro e entre áreas geográficas (Magnusson et al., 2005), sendo escolhida pela praticidade e pelo baixo custo de sua implantação em campo. Foram traçadas 10 linhas paralelas de $50 \mathrm{~m}$ de extensão com distanciamento de $10 \mathrm{~m}$ entre si. As linhas foram marcadas a cada $10 \mathrm{me}$ distribuídas no terreno no sentido oeste-leste em direção à orla da Laguna dos Patos. Foi delimitada uma faixa de $1 \mathrm{~m}$ para cada lado da linha central, totalizando 50 parcelas e uma área amostral de $1.000 \mathrm{~m}^{2}$ (0,1 ha). Foram incluídos os indivíduos com diâmetro à altura do peito (DAP $\geq 4,8 \mathrm{~cm}$ ), identificadas as espécies e estimada a altura. Foram incluídos na amostragem os indivíduos em que a metade do fuste estivesse a $1 \mathrm{~m}$ de distância da linha central. Os indivíduos ramificados foram contados como um indivíduo, sendo mensurados somente os fustes dentro do diâmetro mínimo de inclusão. O trabalho de campo ocorreu entre setembro e novembro de 2006.

Algumas das espécies tiveram material fértil e/ ou vegetativo coletado e processado, conforme as recomendações de Fidalgo \& Bononi (1984), e estão tombadas no Herbário PEL da Universidade Federal de Pelotas. A nomenclatura das espécies está de acordo com o sistema proposto por Angiosperm Phylogeny Group (2009). Avaliou-se a citação da espécie conforme o Decreto Estadual (Rio Grande do Sul, 2014) que lista as espécies da flora ameaçadas de extinção no Estado do Rio Grande do Sul.

Os parâmetros fitossociológicos foram calculados pelo programa "Fitopac 2" (Shepherd, 1995). Para estimar a estrutura da vegetação foram avaliados: densidade absoluta e relativa, frequência relativa e absoluta, dominância relativa e índice de valor de importância. O índice de valor de importância foi dividido por três para permitir a leitura da tabela diretamente em porcentagem (Moro \& Martins, 2011). Para avaliar a diversidade na área foi utilizado o índice de Shannon $\left(H^{\prime}\right)$ e para a equabilidade o índice de Pielou (J'). A altura dos espécimes foi estimada com vara de cinco metros e estratificação vertical em intervalos de classe de um metro.

\section{Resultados}

A riqueza do levantamento fitossociológico foi de 23 espécies, distribuídas em 20 gêneros e 15 famílias. A maior riqueza foi observada para Myrtaceae (5 espécies), seguida de Arecaceae, Euphorbiaceae, Lauraceae e Primulaceae (2 espécies cada) (Tabela 1). Foram amostradas duas espécies ameaçadas de extinção (Geonoma schottiana, em perigo, e Chionanthus filiformis, vulnerável) (Rio Grande do Sul, 2014). Fora da área de amostragem foram encontradas Myrcia palustris, Myrsine parvifolia, Salix humboldtiana e Sapium glandulosum habitando ambientes de mata paludosa. O remanescente possui outras populações ameaçadas de extinção nas espécies Butia odorata, Ephedra tweediana, Dicksonia sellowiana e Quillaja brasiliensis (Brasil, 2014; Rio Grande do Sul, 2014).

$\mathrm{Na}$ Tabela 2, estão apresentados os parâmetros fitossociológicos estimados. As dez primeiras espécies corresponderam a $89 \%$ dos indivíduos amostrados. Por outro lado, 11 espécies ( $48 \%$ do total) tiveram menos de dois indivíduos e contribuição de 4\% na estrutura da comunidade. As espécies de maior valor de importância foram Ocotea sp.; Myrcia multiflora; Psidium cattleianum; Ocotea pulchella; Myrsine lorentziana; Citharexyllum myrianthum; Ilex dumosa; Syagrus romanzoffiana; Guapira opposita e Sebastiania brasiliensis. Entre estas espécies mais importantes, merecem destaque Ocotea sp., Myrcia multiflora, Psidium cattleianum, Ocotea pulchella e Myrsine lorentziana que tiveram alta frequência de ocorrência e número de indivíduos, caracterizando a fisionomia da vegetação. As espécies Citharexyllum myrianthum e Ficus organensis se destacam na estrutura da vegetação pelo porte e altura elevada dos indivíduos. 
Tabela 1. Relação das famílias e nome popular das espécies amostradas no levantamento fitossociológico em uma mata de restinga paludosa na Mata do Totó, município de Pelotas, RS.

\begin{tabular}{|c|c|c|}
\hline Famílias/Espécie & Nome popular & $\mathbf{N}^{0}$ PEL \\
\hline \multicolumn{3}{|l|}{ Anacardiaceae } \\
\hline Lithraea brasiliensis Marchand & aroeira-braba & 23.882 \\
\hline \multicolumn{3}{|l|}{ Aquifoliaceae } \\
\hline Ilex dumosa Reissek & caúna & 24.681 \\
\hline \multicolumn{3}{|l|}{ Arecaceae } \\
\hline Geonoma schottiana Mart.* & geonoma & $\mathrm{nt}$ \\
\hline Syagrus romanzoffiana (Cham.) Glassm & jerivá, coqueiro & $\mathrm{nt}$ \\
\hline \multicolumn{3}{|l|}{ Cardiopteridaceae } \\
\hline Citronella gongonha (Mart.) R.A. Howard & congonha & 24.695 \\
\hline \multicolumn{3}{|l|}{ Euphorbiaceae } \\
\hline Sebastiania brasiliensis Spreng. & branquilho-leiteiro & 24.688 \\
\hline Sebastiania commersoniana (Baill.) L. B. Sm. \& Downs & branquilho & 23.901 \\
\hline \multicolumn{3}{|l|}{ Fabaceae } \\
\hline Erythrina crista-galli $\mathrm{L}$. & corticeira-do-banhado & 23.905 \\
\hline \multicolumn{3}{|l|}{ Lamiaceae } \\
\hline Vitex megapotamica (Spreng.) Moldenke & tarumã & 24.676 \\
\hline \multicolumn{3}{|l|}{ Lauraceae } \\
\hline Ocotea pulchella Mart. & canela-do-brejo & 24.677 \\
\hline Ocotea sp. & canela-do-brejo & nt \\
\hline \multicolumn{3}{|l|}{ Moraceae } \\
\hline Ficus organensis Mig & $\begin{array}{l}\text { figueira-de-folha- } \\
\text { miúda }\end{array}$ & 23.915 \\
\hline \multicolumn{3}{|l|}{ Myrtaceae } \\
\hline Blepharocalyx salicifolius (Kunth) O.Berg & murta & 24.689 \\
\hline Eugenia uruguayensis Cambess. & guamirim & 23.921 \\
\hline Myrcia multiflora (Lam.) DC & cambuí & 24.666 \\
\hline Myrcianthes cisplatensis O.Berg. & araçá-do-prata & 23.924 \\
\hline Psidium cattleianum Sabine & araçá & 24.674 \\
\hline \multicolumn{3}{|l|}{ Nyctaginaceae } \\
\hline Guapira opposita (Vell.) Reitz & maria-mole & 23.928 \\
\hline \multicolumn{3}{|l|}{ Oleaceae } \\
\hline Chionanthus filiformis (Vell.) P.S. Green* & azeitona-do-mato & 24.699 \\
\hline \multicolumn{3}{|l|}{ Primulaceae } \\
\hline Myrsine lorentziana (Mez) Arechav. & capororoca & $\mathrm{nt}$ \\
\hline Myrsine umbellata Mart. & capororocão & 23.917 \\
\hline \multicolumn{3}{|l|}{ Salicaceae } \\
\hline Banara parviflora Benth. & guaçatunga & 23.939 \\
\hline \multicolumn{3}{|l|}{ Verbenaceae } \\
\hline Citharexyllum myrianthum Cham. & tucaneira, tarumã & 23.955 \\
\hline
\end{tabular}


Tabela 2. Parâmetros fitossociológicos da estrutura do componente arbóreo (DAP $\geq 4,8 \mathrm{~cm}$ ) de uma mata de restinga paludosa no Município de Pelotas, RS, Brasil.

\begin{tabular}{|c|c|c|c|c|c|c|c|}
\hline $\mathbf{N}^{\mathbf{o}}$ & Espécies & DA & DR & FA & FR & DoR & $\% \mathrm{VI}$ \\
\hline 1 & Ocotea sp. & 140 & 40,52 & 78 & 18,93 & 33,62 & 31,02 \\
\hline 2 & Myrcia multiflora & 46 & 13,22 & 64 & 15,53 & 6,51 & 11,75 \\
\hline 3 & Psidium cattleianum & 30 & 8,62 & 48 & 11,65 & 4,27 & 8,18 \\
\hline 4 & Ocotea pulchella & 23 & 6,32 & 38 & 9,22 & 5,86 & 7,13 \\
\hline 5 & Myrsine lorentziana & 21 & 6,03 & 34 & 8,25 & 6,68 & 6,99 \\
\hline 6 & Citharexyllum myrianthum & 10 & 2,87 & 18 & 4,37 & 12,79 & 6,68 \\
\hline 7 & Ilex dumosa & 14 & 4,02 & 24 & 5,83 & 9,86 & 6,57 \\
\hline 8 & Syagrus romanzoffiana & 10 & 2,87 & 16 & 3,88 & 3,76 & 3,50 \\
\hline 9 & morta & 11 & 3,16 & 18 & 4,37 & 1,72 & 3,08 \\
\hline 10 & Guapira opposita & 9 & 2,59 & 12 & 2,91 & 3,56 & 3,02 \\
\hline 11 & Sebastiania brasiliensis & 8 & 2,30 & 16 & 3,88 & 1,07 & 2,42 \\
\hline 12 & Sebastiania commersoniana & 8 & 2,30 & 10 & 2,43 & 0,85 & 1,86 \\
\hline 13 & Ficus organensis & 2 & 0,57 & 4 & 0,97 & 3,28 & 1,61 \\
\hline 14 & Erythrina crista-galli & 1 & 0,29 & 2 & 0,49 & 3,58 & 1,45 \\
\hline 15 & Blepharocalyx salicifolius & 4 & 1,15 & 8 & 1,94 & 0,43 & 1,17 \\
\hline 16 & Lithraea brasiliensis & 2 & 0,57 & 4 & 0,97 & 0,72 & 0,75 \\
\hline 17 & Vitex megapotamica & 2 & 0,57 & 4 & 0,97 & 0,16 & 0,57 \\
\hline 18 & Chionanthus filiformis* & 1 & 0,29 & 2 & 0,49 & 0,48 & 0,42 \\
\hline 19 & Citronella gongonha & 1 & 0,29 & 2 & 0,49 & 0,31 & 0,36 \\
\hline 20 & Myrcianthes cisplatensis & 1 & 0,29 & 2 & 0,49 & 0,16 & 0,31 \\
\hline 21 & Eugenia uruguayensis & 1 & 0,29 & 2 & 0,49 & 0,12 & 0,30 \\
\hline 22 & Banara parviflora & 1 & 0,29 & 2 & 0,49 & 0,10 & 0,29 \\
\hline 23 & Geonoma schottiana* & 1 & 0,29 & 2 & 0,49 & 0,06 & 0,28 \\
\hline \multirow[t]{2}{*}{24} & Myrsine umbellata & 1 & 0,29 & 2 & 0,49 & 0,05 & 0,28 \\
\hline & TOTAL & 348 & 100 & & 100 & 100 & 100 \\
\hline
\end{tabular}

* Espécies ameaçadas de extinção. $\mathrm{DA}=$ densidade absoluta; $\mathrm{DR}$ = densidade relativa; $\mathrm{FA}$ = frequência absoluta; $\mathrm{FR}$ = frequência relativa; $\mathrm{DoR}=$ dominância relativa $\mathrm{e} \mathrm{VI}=$ valor de importância 
A diversidade pelo índice de Shannon (H') foi de 2.174 nats.ind.$^{-1} \mathrm{e}$ a equabilidade de Pielou (J') de 0,684. A abundância foi de 348 indivíduos e nestes foram encontrados 11 indivíduos mortos que ainda se encontravam em pé, correspondentes a 3,1\% do total. A família mais abundante foi Lauraceae (163), seguida de Myrtaceae (79). As famílias Lauraceae e Myrtaceae englobaram 69\% da densidade absoluta da comunidade amostrada. Os diâmetros à altura do peito (DAP) variaram do limite de inclusão (DAP $\geq$ $4,8 \mathrm{~cm}$ ) até $81 \mathrm{~cm}$ para um indivíduo ramificado de Citharexyllum myrianthum. Outras espécies obtiveram diâmetro do fuste elevado para pelo menos uma árvore, como Ocotea sp. (51 cm - ramificado), Ilex dumosa (43 $\mathrm{cm}$ - ramificado) e Erythrina crista-galli $(43 \mathrm{~cm})$.

A ramificação do fuste foi encontrada em 38 indivíduos de nove espécies (Ilex dumosa, Citharexyllum myrianthum, Myrcia multiflora, Ocotea sp., Psidium cattleianum, Myrsine lorentziana, Citharexyllum myrianthum, Guapira opposita e Sebastiania brasiliensis). Esse total representa 10,9\% dos indivíduos amostrados.

A altura média da comunidade foi de $7,3 \mathrm{~m}$, com um único pico modal no dossel (Figura 2). Um percentual de $83 \%$ dos indivíduos se encontra entre $5 \mathrm{~m}$ e $9 \mathrm{~m}$ de altura. As espécies Myrcia multiflora, Sebastiania brasiliensis e Geonoma schotianna ocorrem no estrato inferior da mata, em condição de sub-bosque ensolarado. O dossel foi composto de Ocotea sp., Ilex dumosa, Citharexyllum myrianthum, Ocotea pulchella, Ficus organensis, Guapira opposita, Psidium cattleianum e Myrsine lorentziana. As maiores alturas foram estimadas para Citharexyllum myrianthum (13 m), Ocotea sp. (12 m), Syagrus romanzoffiana, Ficus organensis e Guapira opposita $(11 \mathrm{~m})$.

A área basal estimada foi de $40,8 \mathrm{~m}^{2}$ e a distribuição em classes de diâmetro de todos os indivíduos da comunidade mostra a predominância de árvores nos dois primeiros intervalos, onde se encontram $82 \%$ dos indivíduos inventariados (Figura 3).

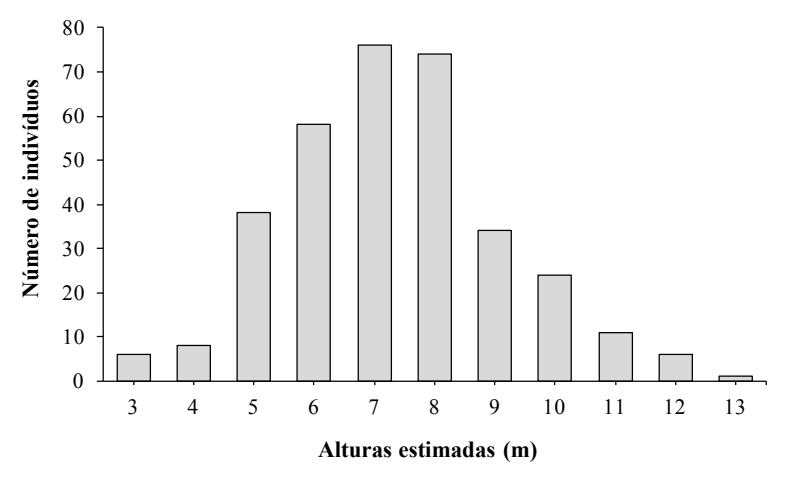

Figura 2. Relação entre o número de indivíduos pela altura estimada em classes de intervalo em levantamento de uma mata de restinga paludosa na Mata do Totó, Pelotas, RS.

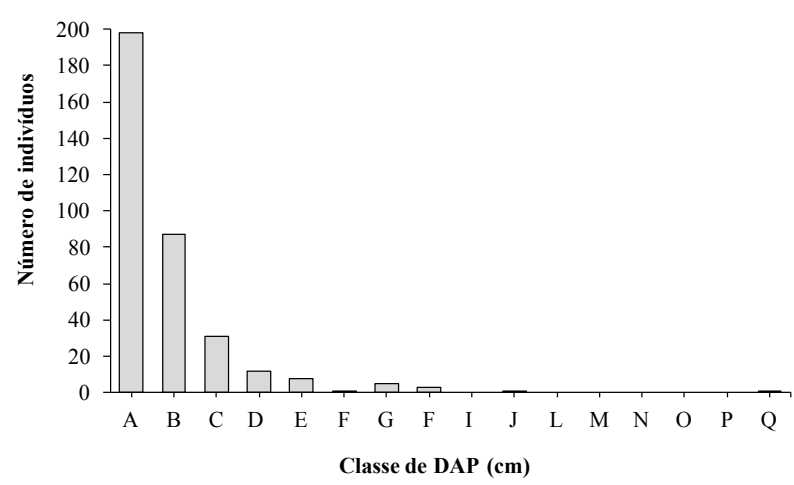

Figura 3. Distribuição do número de indivíduos por classes de diâmetro de $5 \mathrm{~cm}$ na mata de restinga paludosa na Mata do Totó, Pelotas, RS, onde: $\mathrm{A}=4,8-9,9 \mathrm{~cm}, \mathrm{~B}=10-14,9 \mathrm{~cm}, \mathrm{C}=15-19,9$ $\mathrm{cm}, \mathrm{D}=20-24,9 \mathrm{~cm} . . ., \mathrm{Q}=80-84,9 \mathrm{~cm}$.

Pesq. flor. bras., Colombo, v. 35, n. 82, p. 101-110, abr.jun. 2015 


\section{Discussão}

A riqueza encontrada englobou $15,5 \%$ das espécies arbóreas e arborescentes amostradas para o Município de Pelotas (Venzke, 2012) e 4,4\% da riqueza inventariada para o Estado do Rio Grande do Sul (Reitz et al., 1983; Sobral et al., 2006). Foram encontradas duas espécies ameaçadas de extinção (Rio Grande do Sul, 2014). A palmeira Geonoma schottiana Mart. que é característica e exclusiva da mata pluvial atlântica no sul do Brasil (Reitz, 1974), espécie que habita solos brejosos e ambiente florestal esciófito em bom estado de conservação (Waechter et al., 2000; Kindel, 2002; Sztutman \& Rodrigues, 2002; Dorneles \& Waechter, 2004; Venzke et al., 2012; Martins et al., 2013). Outra espécie ameaçada é Chionanthus filiformis (Vell.) P.S.Green que também foi coletada na localidade denominada "Cerro das Almas", que é um remanescente preservado de Floresta Estacional Semidecidual de encosta na região do Município de Pelotas (Souza, 1999). Chionanthus filiformis ocorreu somente na mata turfosa deste estudo, quando comparado com outros 16 levantamentos realizados com componente arbóreo na Planície Costeira do Rio Grande do Sul (Venzke et al., 2012). Apesar da coleta realizada em uma área amostral reduzida, a ocorrência destas espécies salienta a importância do local para a preservação de espécies ameaçadas de extinção.

As famílias mais abundantes, Myrtaceae e Lauraceae, são comuns em outras áreas de florestas brasileiras sob solos com saturação hídrica (Toniato et al., 1998; Sztutman \& Rodrigues, 2002; Dorneles \& Waechter, 2004; Loures et al., 2007; Menezes et al., 2010; Martins et al., 2013). Myrtaceae possui densidade elevada para diferentes formações florestais riograndenses (Klein, 1984; Farias et al., 1994; Waechter \& Jarenkow, 1998; Longhi et al., 1999; Jurinitz \& Jarenkow, 2003; Budke et al., 2004; Dorneles \& Waechter, 2004; Scherer et al., 2005; Martins et al., 2013), além de ser a família botânica de maior riqueza específica na flora arbórea do Rio Grande do Sul (Reitz et al., 1983; Sobral, 2003; Sobral et al., 2006). Outras famílias com número significativo de indivíduos na Mata do Totó foram Primulaceae (22), Euphorbiaceae (16) e Aquifoliaceae (14), que são comuns em outras florestas em condições de encharcamento do solo (Ivanauskas et al., 1997; Dorneles \& Waechter, 2004; Loures et al., 2007; Martins et al., 2013).
A densidade estimada (3.480 indivíduos ha-1) é elevada para florestas. Porém, é semelhante ao encontrado em comunidades florestais em solos com encharcamento permanente (Toniato et al., 1998; Kindel, 2002; Sztutman \& Rodrigues, 2002; Dorneles \& Waechter, 2004; Loures et al., 2007; Martins et al., 2013). A elevada densidade absoluta formada por baixa riqueza representa a alta dominância ecológica de poucas espécies nas comunidades sob solos encharcados (Martins et al., 2013).

Essas matas paludosas, juntamente com matas ciliares localizadas na Planície Costeira do Rio Grande do Sul possuem dossel relativamente baixo, com indivíduos apresentando altura máxima de $18 \mathrm{~m}$ (Waechter \& Jarenkow, 1998; Kilca, 2002; Kindel, 2002; Dorneles \& Waechter, 2004; De Marchi \& Jarenkow, 2008). A baixa altura dessas florestas pode ser explicada pela limitação que o solo impõe ao desenvolvimento do sistema radicular dos indivíduos. A saturação hídrica promove o crescimento de raízes superficiais decorrentes da constante superficialidade do lençol freático, que juntamente com a instabilidade do solo (Kindel, 2002; Dorneles \& Waechter, 2004; Loures et al., 2007) amplia a possibilidade de tombamento dos indivíduos mais altos em razão da pouca profundidade das raízes (Bianchini et al., 2003). Uma das espécies mais altas na Mata do Totó é Ficus organensis, que possui raízes tabulares que aumentam a sustentação e parecem reduzir a probabilidade de queda de indivíduos dessa espécie (Kindel, 2002). Outro fator limitante é a posição da mata, no perímetro com a Laguna dos Patos, expondo a vegetação às forças do vento que, juntamente com as características fitoedáficas do substrato, ampliam a possibilidade de queda dos indivíduos maiores.

Quanto à diversidade, o valor estimado na Mata do Totó é baixo para levantamentos fitossociológicos no Brasil. Contudo, o valor reduzido é parâmetro normal em comunidades sob saturação hídrica do solo, que apresentam baixa diversidade independente da latitude ou região biogeográfica (Torres et al., 1994; Ivanauskas et al., 1997; Waechter \& Jarenkow, 1998; Imbert et al., 2000; Cattanio et al., 2002; Kindel, 2002; Sztutman \& Rodrigues, 2002; Teixeira \& Assis, 2005; Scarano, 2006; Martins et al., 2013). Valores menores de diversidade no Brasil foram encontrados em mata paludosa (1,30 nats ind..$^{-1}$ ) (Scarano, 2006); em Floresta Ombrófila Densa aluvial sob condições drásticas de recrutamento de plântulas causadas por inundações periódicas $(1,30$ nats 
ind. $^{-1}$ ) (Valente et al., 2011); em área de Mata Atlântica que foi queimada e usada como pastagem durante 30 anos e com 10 anos de regeneração natural (1,16 nats ind. $^{-1}$ ) (Tabarelli \& Mantovani, 1999); em turfeira profunda com mais de $5 \mathrm{~m}$ de profundidade $(0,82$ nats ind..$^{-1}$ ) (Sztutman \& Rodrigues, 2002) e em comunidade subtropical Savana Estépica com monodominância de Prosopis affinis e Prosopis nigra (0,71 nats ind.$\left.^{-1}\right)$ (Watslawick et al., 2010). A diversidade natural baixa dessas comunidades vegetais deve ser levada em consideração na avaliação da estrutura dessas formações vegetais em projetos de restauração ecológica.

O encharcamento edáfico ao qual as matas paludosas estão condicionadas constitui um dos principais fatores abióticos selecionadores da ocorrência das espécies vegetais (Torres et al., 1994) e atua como um fator limitante para a maioria das espécie (Porto \& Dillenburg, 1986). As plantas nestes solos estão submetidas ao estresse fisiológico da ausência de oxigênio, da elevada toxidez provocada pelo alto teor de $\mathrm{Al}^{+3}$ e de valores elevados de $\mathrm{H}+\mathrm{Al}$ e $\mathrm{pH}$ do solo extremamente baixo (Martins, et al, 2013). A limitação do substrato reflete na ausência de espécies comuns das matas arenosas da planície costeira do Rio Grande do Sul habitando a mata paludosa de substrato encharcado permanentemente. Entre estas se destacam Erythroxylum argentinum, Casearia silvestris, Casearia decandra, Zanthoxylum fagara, Diospyros inconstans, Chrysophyllum marginatum, Myrrhinium atropurpureum, Dodonaea viscosa e Allophylus edulis (Dillenburg et al., 1992; Rossoni, 1993; Waechter et al., 2000; Moraes \& Mondin, 2001; Dorneles \& Waechter, 2004; Scherer et al., 2005; Venzke et al., 2012).

\section{Conclusões}

A riqueza de espécies e de famílias é baixa, consistente com a vegetação de matas paludosas de planícies costeiras do Brasil. Os parâmetros fitossociológicos mostram uma floresta de altura baixa, densidade elevada e diversidade baixa. A estrutura da floresta foi constituída por espécies higrófitas e adaptadas ao excesso de umidade com os vegetais Citharexylum myrianthum, Ilex dumosa, Ocotea pulchella, Ocotea sp., Psidium cattleianum, Myrcia multiflora, Myrsine lorentziana, Syagrus romanzoffiana e Guapira opposita. Salienta-se que numa pequena área amostral foram registradas duas espécies ameaçadas de extinção. Espécies características de ambientes de melhor drenagem foram amostradas, porém com reduzida abundância. Essa preferência das espécies por certos nichos ecológicos indica que nos plantios de reflorestamento é indicado escolher as plantas conforme o seu habitat preferencial no meio ambiente, a fim de maximizar ambiental e economicamente projetos de restauração ecológica.

O remanescente florestal da Mata do Totó, entre outros na região, é provavelmente o limite da distribuição geográfica para alguns táxons tropicais. Deste modo, o local é importante para a conservação da biodiversidade na planície costeira do extremo sul do Brasil. Aconselhase a criação de uma Unidade de Conservação na Mata do Totó, conciliando a atividade turística da população com a conservação deste remanescente de mata de restinga. Para minimizar impactos ambientais no local é necessário regularizar a área como uma unidade de conservação e a elaboração de plano de manejo.

\section{Referências}

ANGIOSPERM PHYLOGENY GROUP. An update of the angiosperm phylogeny group classification for the orders and families of flowering plants: APG III. Botanical Journal of the Linnean Society, London, v. 161, p. 105-121, 2009.

BIANCHINI, E.; POPOLO, R. S.; DIAS, M. C.; PIMENTA, J. A. Diversidade e estrutura de espécies arbóreas em área alagável do Município de Londrina, Sul do Brasil. Acta Botanica Brasilica, Feira de Santana, v. 17, n. 3, p. 405-419, 2003.

BRASIL. Conselho Nacional de Meio Ambiente. Resolução n ${ }^{\circ} 7$, de 23 de julho de 1996. Diário Oficial [da] República Federativa do Brasil, Brasília, DF, n. 165, 26 ago. 1996.

BRASIL. Lei Federal no 11.428, de 22 de dezembro de 2006. Dispõe sobre a utilização e proteção da vegetação nativa do Bioma Mata Atlântica e dá outras providências. 2006. Diário Oficial [da] República Federativa do Brasil, Brasília, DF, n. 245, 22 dez. 2006.

BRASIL. Lei $n^{\circ} 12.651$, de 25 de maio de 2012. Dispõe sobre a proteção da vegetação nativa e dá outras providências. 2012. Diário Oficial [da] República Federativa do Brasil, Brasília, DF, n. 102, 28 maio, 2012.

BRASIL. Portaria ${ }^{\circ}$ 443, de 17 de dezembro de 2014. Lista nacional oficial de espécies da flora ameaçadas de extinção. 2014. Diário Oficial [da] República Federativa do Brasil, Brasília, DF, n. 110, 18 dezembro, 2014.

BUDKE, J. C.; GIEHL, E. L. H; ATHAYDE, E. A.; EISINGER, S. M; ZACHIA, R. A. Florística e fitossociologia do componente arbóreo de uma floresta ribeirinha, Arroio Passo das Tropas, Santa Maria, RS, Brasil. Acta Botanica Brasilica, Feira de Santana, v. 18, n. 3, p. 581-589, 2004.

CATTANIO, J. H.; ANDERSON, A. B.; CARVALHO, M. S. Floristic composition and topographic variation in a tidal floodplain forest in the Amazon Estuary. Revista Brasileira de Botânica, São Paulo, v. 25, n. 4, p. 419-430, 2002. 
CARVAlHO, F. A.; NASCIMENTO, M. T.; BRAGA, J. M. A.; RODRIGUES, P. J. F. P. Estrutura da comunidade arbórea da floresta atlântica de baixada periodicamente inundada na Reserva Biológica de Poço das Antas, Rio de Janeiro, Brasil. Rodriguesia, Rio de Janeiro, v. 57, n. 3, p. 503-518, 2006.

DE MARCHI, T. C.; JARENKOW, J. A. Estrutura do componente arbóreo de mata ribeirinha no rio Camaquã, município de Cristal, Rio Grande do Sul, Brasil. Iheringia: Série Botânica, Porto Alegre, v. 63 , p. 241-248, 2008.

DILLEMBURG, L. R.; WAECHTER, J. L.; PORTO, M. L. Species composition and structure of a sand coastal plain forest in northern Rio Grande do Sul, Brazil. In: SEELIGER, U. (Ed.) Coastal plant communities of Latin America. New York: Academic Press, 1992. p. 349-366.

DORNELES, L. P. P.; WAECHTER J. L. Fitossociologia do componente arbóreo na floresta turfosa do Parque Nacional da Lagoa do Peixe, Rio Grande do Sul, Brasil. Acta Botanica Brasilica, Feira de Santana, v. 18, n. 4, p. 815-824, 2004.

TEMPERATURA média $\left({ }^{\circ} \mathrm{C}\right)$ e precipitação pluviométrica $(\mathrm{mm})$ - período: 1971/2000 (mensal/anual). Capão do Leão: Embrapa; UFPel; INMET, 2011. Disponível em: <http://www.cpact.embrapa. br/agromet/estacao/mensal.html>. Acesso em: 05 abr. 2015.

FARIAS, A. C.; TEIXEIRA, I. F.; PES, L.; ALVAREZ-FILHO, A. Estrutura fitossociológica de uma Floresta Estacional Decidual na Região de Santa Maria, RS. Ciência Florestal, Santa Maria, RS, v. 4, n. 1, p. 109-128, 1994.

FIDALGO, O.; BONONI, V. L. R. Técnicas de coleta, preservação e herborização de material botânico. São Paulo: Instituto de Botânica, 1984. 60 p.

GENTRY, A. Patterns of neotropical plant species diversity. Evolutionary Biology, New York, v. 15, p. 1-84, 1982.

IBGE. Levantamento de recursos naturais: Vegetação. Rio de Janeiro, 1986. p. 541-632.

IBGE. Manual técnico da vegetação Brasileira. 2. ed. Rio de Janeiro, 2012. 274 p. (IBGE. Manuais técnicos em geociências, 1).

IMBERT, D.; BONHÊME, I.; SAUR, E.; BOUCHON, C. Floristic and structure of the Pterocarpus officinalis swamp forest in Guadeloupe, Lesser Antilles. Journal of Tropical Ecology, Cambridge, v. 16, p. 55-68, 2000.

IVANAUSKAS, N. M.; RODRIGUES, R. R.; NAVE, A. G. Aspectos ecológicos de um trecho de Floresta de brejo em Itatinga, SP: florística, fitossociologia e seletividade de espécies. Revista Brasileira de Botânica, São Paulo, v. 20, n. 2, p. 139-153, 1997.

JURINITZ, C. F.; JARENKOW, J. A. Estrutura do componente arbóreo de uma floresta estacional na Serra do Sudeste, Rio Grande do Sul, Brasil. Revista Brasileira de Botânica, São Paulo, v. 26, n. 4, p. 475-487, 2003.

KILCA, R. V. Alguns aspectos florísticos e estruturais de uma floresta galeria no Sul da Planície Costeira do Rio Grande do Sul. 2002. 80 f. Monografia (Graduação em Ciências Biológicas) Universidade Federal de Pelotas, Pelotas.
KINDEL, A. Diversidade e estratégias de dispersão de plantas vasculares da floresta paludosa do Faxinal, Torres - RS. 2002. 102 f. Tese (Doutorado em Botânica) - Universidade Federal do Rio Grande do Sul, Porto Alegre.

KLEIN, R. M. Importância fitossociológica das Mirtáceas nas florestas Riograndenses. In: CONGRESSO NACIONAL DE BOTÂNICA, 24, 1984, Porto Alegre. Anais... Porto Alegre: Sociedade de Botânica do Brasil, 1984. p. 367-375.

KÖPPEN, W. P. Climatologia: con un estudio de los climas de la Tierra. Mexico: Fondo de Cultura Economica, 1948. 478 p.

LONGHI, S. J.; NASCIMENTO, A. R. T.; FLEIG, F. D.; DELLAFLORA, J. B.; FREITAS, R. A.; CHARÃO, L. W. Composição florística e estrutura da comunidade arbórea de um fragmento florestal no Município de Santa Maria, Brasil. Ciência Florestal, Santa Maria, RS, v. 9, n. 1, p. 115-133, 1999.

LOURES, L.; CARVAlHO, D. A.; MACHADO, E. L. M.; MARQUES, J. J. G. S. M. Florística, estrutura e características do solo de um fragmento de floresta paludosa no sudeste do Brasil. Acta Botanica Brasilica, Feira de Santana, v. 21, n. 4, p. 885-896, 2007.

MAGNUSSON, W. E.; LIMA, A. P.; LUIZÃO, F.; COSTA, F. R. C.; CASTILHO, C. W. de; KINUPP, V. F. Rapeld: a modification of the Gentry Method for biodiversity surveys in long-term ecological research sites. Biota Neotropica, Campinas, v. 5, n. 2, p. 1-6, 2005.

MARTINS, R.; JARENKOW, J. A.; GHIEL, E. L. H.; CITADINIZANETTE, V.; SANTOS, R. Estrutura de uma floresta brejosa em substrato turfoso, sul de Santa Catarina, Brasil. Revista Árvore, Viçosa, MG, v. 37, n. 2, p. 299-309, 2013.

MENEZES, L. F. T.; ARAUJO, D. S. D.; NETTESSHEIM, F. C. Estrutura comunitária e amplitude ecológica do componente lenhoso de floresta de restinga mal drenada no sudeste do Brasil. Acta Botanica Brasilica, Belo Horizonte, v. 24, n. 3, p. 825-839, 2010.

MORAES, D.; MONDIN, C. A. Florística e fitossociologia do estrato arbóreo em mata arenosa no balneário do Quintão, Palmares do Sul, Rio Grande do Sul. Pesquisas, Botânica, São Leopoldo, n. 51, p. 87-100, 2001.

MORO, M. F.; MARTINS, F. R. Métodos de levantamento do componente arbóreo-arbustivo. In: FELFINI, J. M.; EISENLOHR, P. V.; MELO, M. M. R. F.; ANDRADE, L. A. A.; NETO, J. A. A. M (Ed.). Fitossociologia no Brasil: métodos e estudos de caso. Viçosa, MG: Ed da UFV, 2011. p. 174-212.

PELOTAS (Prefeitura Municipal). Lei no 4336 de 18 de dezembro de 1998. Declara de valor paisagístico e ecológico a Mata do Totó. 1998. Disponível em: $<$ http://www.pelotas.rs.gov.br/interesse_legislacao/ leis/antigo/L1998/Lei_n_4.336.pdf>. Acesso em: 24 nov. 2006.

PORTO, M. L.; DILLENBURG, L. R. Fisionomia e composição florística de uma mata de restinga da Estação Ecológica do Taím, Brasil. Ciência e Cultura, Campinas, v. 38, n. 7, p. 1229-1236, 1986. REITZ, R. Palmeiras. In: REITZ, R. (Ed.). Flora ilustrada catarinense. Itajaí: Herbário Barbosa Rodrigues, 1974. p. 3-189.

REITZ, R; KLEIN, R. M; REIS, A. Projeto Madeira do Rio Grande do Sul. Sellowia, Itajaí, v. 34-35, p. 1-526, 1983. 
RIO GRANDE DO SUL. Decreto $n^{0}$ 52.109, de 19 de dezembro de 2014. Espécies da flora nativa ameaçadas de extinção no Estado do Rio Grande do Sul. 2014. Disponível em: <http://www.fzb.rs.gov.br/ downloads/flora_ameacada.pdf $>$. Acesso em: 09 jan. 2015.

ROSSONI, M. G. Estudo fitossociológico da mata de restinga, no balneário de Rondinha Velha, Arroio do Sal, RS. 1993. 73 f. Dissertação (Mestrado em Botânica) - Universidade Federal do Rio Grande do Sul, Porto Alegre.

SCARANO, F. R. Plant community structure and function in a swamp forest within the Atlantic Rain Forest complex: a synthesis. Rodriguésia, Rio de Janeiro, n. 57, p. 491-502, 2006.

SCHERER, A.; MARASCHIN-SILVA, F.; BAPTISTA, L. R. M. Florística e estrutura do componente arbóreo de matas de Restinga arenosa no Parque Estadual de Itapuã, RS, Brasil. Acta Botanica Brasilica, Feira de Santana, v. 19, n. 4, p. 717-726, 2005.

SEEligeR, U.; ODEBRECHT, C.; CASTELlO, J. P. Os ecossistemas costeiro e marinho do extremo sul do Brasil. Rio Grande, RS: Editora Ecoscientia, 1998. 326 p.

SHEPHERD, G. J. Fitopac 1: manual do usuário. Campinas: Ed da Unicamp, 1995. $17 \mathrm{p}$.

SOBRAL, M. A família Myrtaceae no Rio Grande do Sul. São Leopoldo: Ed da Unisinos, 2003. 215 p.

SOBRAL, M.; JARENKOW, J. A.; BRACK, P.; IRGANG, B.; LARROCA, J.; RODRIGUES, R. S. Flora arbórea e arborescente do Rio Grande do Sul. São Carlos, SP: Novo Ambiente, 2006. 350 p.

SOUZA, C. A. Florística e aspectos ecológicos do componente arbóreo de uma área com mata de encosta em Pelotas, RS. Pelotas. 1999. 30 f. Monografia (Bacharelado em Biologia) - Universidade Federal de Pelotas, Pelotas.

SZTUTMAN, M.; RODRIGUES, R. R. O mosaico vegetacional numa área de floresta contínua da planície litorânea, Parque Estadual da Campina do Encantado, Pariquera- Açu, SP. Revista Brasileira de Botânica, São Paulo, v. 25, n. 2, p. 61-176, 2002.

TABARELLI, M.; MANTOVANI, W. A regeneração de uma floresta tropical Montana após corte e queima (São Paulo - Brasil). Revista Brasileira de Biologia, São Carlos, v. 59, n. 2, p. 239-250, 1999.

TEIXEIRA, A. P.; ASSIS, M. A. Caracterização florística e fitossociológica do componente arbustivo-arbóreo de uma floresta paludosa no Município de Rio Claro (SP), Brasil. Revista Brasileira de Botânica, São Carlos, SP, v. 28, n. 3, p. 467-476, 2005.

TOMAZELLI, L. J.; VILWOCK, J. A. Mapeamento geológico de Planícies Costeiras: o Exemplo da costa do Rio Grande do Sul. Gravel, Porto Alegre, n. 3, p. 109-115, 2005.

TONIATO, M. T. Z.; LEITÃO-FILHO, H. F.; RODRIGUES, R. R. Fitossociologia de um remanescente de floresta higrófila (mata de brejo) em Campinas, SP. Revista Brasileira de Botânica, São Paulo, v. 21, n. 2, p. 197-210, 1998.
TORRES, R. B.; MATTHES, L. A. F.; RODRIGUES, R. R. Florística e estrutura do componente arbóreo de uma mata de brejo em Campinas, SP. Acta Botanica Brasilica, Feira de Santana, v. 17, n. 2, p. 189-194, 1994.

VALENTE, A. S. M.; GARCIA, P. O.; SALIMENA, F. R. G.; OLIVEIRA-FILHO, A. T. Composição, estrutura e similaridade florística da Floresta Atlântica, na Serra Negra, Rio Preto, MG. Rodriguésia, Rio de Janeiro, v. 62, n. 2, p. 321-340, 2011.

VENZKE, T. S. Florística de comunidades arbóreas no Município de Pelotas, Rio Grande do Sul, extremo sul do Brasil. Rodriguesia, Rio de Janeiro, v. 63, n. 3, p. 571-578, 2012.

VENZKE, T. S.; FERRER, R. S.; COSTA, M. A. D. Florística e análise de similaridade de espécies arbóreas da Mata da Praia do Totó, Pelotas, RS, Brasil. Ciência Florestal, Santa Maria, RS, v. 22, n. 4, p. 655-668, 2012.

VENZKE, T. S. L. Levantamento florístico como subsídio para a criação de uma unidade de conservação na Praia do Totó, Pelotas, RS. In: SIMPÓSIO DE ÁREAS PROTEGIDAS, III, 2005, Pelotas. Anais... Pelotas: Universidade Católica de Pelotas, 2005. p. 66-71.

WAECHTER, J. L. Aspectos ecológicos da vegetação de Restinga no Rio Grande do Sul. Comunicação do Museu de Ciências, Porto Alegre, v. 33, p. 49-68, 1985.

WAECHTER, J. L. Comunidades vegetais das restingas do Rio Grande do Sul. In: SIMPÓSIO DE ECOSSISTEMAS DA COSTA SUL E SUDESTE BRASILEIRA, II, 1990, Águas de Lindóia. Anais... Águas de Lindóia: ACIESP, São Paulo, 1990. p. 228-248.

WAECHTER, J. L.; JARENKOW, J. A. Composição e estrutura do componente arbóreo nas matas turfosas do Taím, RS. Biotemas, Florianópolis, v. 11, n. 1, p. 45-69, 1998.

WAECHTER, J. L.; MÜLLER, S. C.; BREIER, T. B.; VENTURI, S. Estrutura do componente arbóreo em uma floresta subtropical de planície costeira interna. In: SIMPÓSIO DE ECOSSISTEMAS BRASILEIROS, V, 2000, São Paulo. Anais... São Paulo: Aciesp, 2000. p. 92-112.

WATZLAWICK, L. F.; LONGHI, S. J.; SCHNEIDER, P. R.; FINGER, C. A. G.; LONGHI, R. V. Caracterização e dinâmica da vegetação de uma Savana Estépica Parque, Barra do Quaraí, RS. Pesquisa Florestal Brasileira, Colombo, v. 30, n. 64, 363-368, 2010. DOI: $10.4336 / 2010$.pfb.30.64.363

ZACARIAS, R. R.; BRITEZ, R. M.; GALVÃO, F; BOEGER, M. R. T. Fitossociologia de dois trechos de Floresta Ombrófila Densa Aluvial em solos hidromórficos, Paraná, Brasil. Floresta, Curitiba, v. 42, n. 4, p. 769-782, 2012. 